book will prove invaluable in these respects. The general principles of fracture diagnosis and treatment are well and clearly outlined, and methods of treatment are described without the lengthy technical details which would be necessary in a book written for the specialist. The book is interestingly written, well illustrated and not difficult to read or understand.

Mr. Coltart in revising the second edition has included most of the modern methods in use, and particularly those which were widely employed during the recent war. He has not mentioned the Kuntscher nail as one of the more modern methods of internal fixation, but then this is by no means a type of treatment to be carried out in general practice.

In dealing with the dislocations of the shoulder a full description of the 'Kocher's' method of reduction is given. There might have been a place for the description of the modified 'Hippocratic' method which many surgeons prefer nowadays. The avoidance of too early movements in the programme of after treatment might have been stressed more, so as to prevent the complication of recurrent dislocation. In the treatment of the latter condition the Nicola method is mentioned together with that of Bankart, whereas present-day experience in this country favours that of the Bankart or Putti-Platt procedures, rather than the Nicola.

This book should be of great value not only to general practitioners but also to students and recently-qualified men to whom the general principles and aims of treatment of these common injuries are of very real importance. It is a book that can easily be used in conjunction with one of the larger technical manuels for the more specialized worker.

W. Alexander Law

\section{KAYNE, PAGEL AND O'SHAUGHNESSY'S PULMONARY TUBERCULOSIS}

By Walter Pagel, M.D., F. A. H. Simmonds, M.A., M.D., D.P.H., N. MCDonald, M.B., M.R.C.P., and L. FATTI, F.R.C.S. 2nd Edition. Pp. xviii +720 with many illustrations. London: Geoffrey Cumberlege, Oxford University Press. 1949. 63s.

This book, already well known to British readers, has been revised and thoroughly brought up to date after an interval of ten years. Since the first edition appeared two of the original authors, Dr. Gregory Kayne and Mr. L. O'Shaughnessy, have died. Dr. Pagel has now gathered around him a fresh team of experts who have produced a second edition which bears favourable comparison with the former volume.

In stating that Dr. Pagel's personal contribution on the pathology of the disease dominates the book we do not wish to cast any slur upon those of the other authors. Dr. Pagel's extensive researches upon the subject entitles him to all the space he needs, and he has used it to present a lucid and complete account of the natural evolution of the tuberculous process in man, which ranks high.
Pathology is only one of the five sections into which this book has been divided; the others being Diagnosis, Prognosis, Management and Epidemie ology and Prevention. In all these sections current tendencies and recent developments have beero given their rightful place and the whole book can be recommended as an excellent account of the best British phthisiological practice. It is freel illustrated and each chapter is equipped with good bibliography.

N. Lloyd Rusby के NEUROLOGICAL ANATOMY IN RELATION $\vec{P}$
TO CLINICAL MEDICINE

By Dr. A. Brodal. Pp. xv +496 , with 94 illustra tions. London: Geoffrey Cumberlege, Oxford University Press. 1948. 42s.

Clinical neurologists will welcome this excellenff book which has been specially prepared to meet a definite need. A textbook of neurological anatom\& written to assist clinicians has long been required and Dr. Brodal is to be congratulated on the success ${ }^{\circ}$ with which he has accomplished this difficult task? The library of every medical school should have this book as those teaching medicine and neurologyare constantly being asked complicated questions by students and postgraduates who have been unable to find the information they require in the usuaw standard works.

Structure and function have to be grasped at $\stackrel{\text { ghe }}{\mathrm{c}}$ same time and Dr. Brodal has stressed this through of out. A full index and extensive bibliography comiplete this scholarly work.

\section{TEXTBOOK OF SURGERY}

M.G.A.

By Patrick KIELY, B.Sc., M.D., M.Ch.(N.U.I.) $\stackrel{\mathbb{\Phi}}{\mathbb{2}}$ F.R.C.S.(Eng.). Pp. vii $+1,184$, with 61 illustrations and 4 colour plates. London $\frac{9}{5}$ H. K. Lewis \& Co., Ltd. 1949. 45s.

This book is a new general textbook of surger intended for the student. The author has avoided long descriptions of operative procedures but has managed to include a huge amount of surgical in formation. 330 pages are given to orthopaedic surgery and fractures, and chapters on E.N.T. surgery, ophthalmic surgery and gynaecology are also included. As a result of this, space is cramped and there is little differentiation between the ims portant and the less important principles; pre sumably for the same reason the illustrations are small and not always distinct. There is no biblio graphy.

The text generally is accurate and informed, and pathology and diagnosis are well described. Treat ment, on the other hand, is conservative and hardlyo up-to-date. For example, no mention is made o hormonal treatment of advanced breast cancer nos of anastomosis of stomach or jejunum to oesophagus for malignant disease of that organ, while the advised treatment for severe or recurrent haema:temesis from peptic ulcer is posterior gastro $\overline{0}$ jejunostomy with infolding of the ulcer. 
The author has succeeded in meeting adequately the needs of the undergraduate, but his work is not likely to be widely used as a book of reference

\section{W.B.}

\section{THE SCIENCE AND ART OF JOINT MANIPULATION}

\section{Vol. 1. The Extremities}

By James Mennell, M.A., M.D., B.C.(Cantab.). and Edition. Pp. 215, with 299 illustrations. London: J. \& A. Churchill. 1949. 24s.

Here we have the second edition of Dr. Mennell's monograph on 'Manipulation of the Extremities.' Volume 2, on ' Joints of the Spinal Column,' he states in his preface, has been held up owing to the ' tremendous amount of very hard work' involved.

Certainly the amount of work that must have been involved in the preparation of this volume is prodigious, and is characteristic of the author. Sufficient to say that he discusses the anatomy of all the joints of the extremities-even the smallestin the utmost detail and, on anatomical grounds, discusses their manipulation in similar detail.

Is this work of value to the orthopaedic surgeon and the physician or only to the full-time manipulator? And is anyone other than an orthopaedic surgeon or a physician in a position to judge when manipulation is . indicated? These are vexed questions. There is no doubt that all interested in orthopaedics and physical medicine will benefit by careful reading of this work.

\section{R.S.H.}

\section{MODERN PRACTICE IN OPHTHALMOLOGY 1949}

Edited by H. B. StallaRd, M.B.E., M.D., F.R.C.S. Pp. $x x+525$, with 231 illustrations, many in colour. London: Butterworth \& Company. 1949. 65s.

The purpose of this book which has been written by a team of specialists is to provide the general practitioner with an outline of modern ophthalmic practice from a practical angle.

The introductory chapters on general subjectsanatomy and physiology, pathology, medical ophthalmology, methods of examination and general therapeutics-are for the most part admirably straightforward and informative.

Of the chapters dealing with specific structures and diseases of the eye, those on the lids, the conjunctiva and the retina are also clearly and simply instructive. The others, though naturally wellinformed, are not, one feels, set out in such a manner as to provide clear guides to diagnosis or sufficiently detailed in the matter of treatment. The uninitiated would, for example, still be at a loss as to how to diagnose and treat a hypopyon ulcer after reference to the interesting chapter on the cornea. Glaucoma might be more clearly sign posted. Injuries are hardly given the space they merit.

Errors of refraction are dealt with in considerable but readable detail and the chapter on strabismus and heterophoria is excellent. There is also a short $\frac{2}{3}$ but instructive chapter on tropical ophthalmology. $\stackrel{\mathbb{D}}{\stackrel{2}{2}}$

The final chapter on operations contains many $c$ excellent illustrations but is disappointing in that space is devoted to one or two highly specialized $\stackrel{\vec{\rho}}{\rightarrow}$ operations of arguable value which might have been $\vec{\partial}$ better filled by details of emergency operations. There is a useful appendix on visual standards required for various services.

The book which is most readable is intended, as the preface states, to enable the general practitioner \& to share with the specialist in the responsibility of $\vec{D}$ treating cases of ocular disease as well as to act on ? his own when unable to seek specialist help. The first of these aims is admirably achieved, but in the $\stackrel{\omega}{\sigma}$ latter the book is not so successful.

\section{A.L.}

\section{BROMPTON HOSPITAL REPORTS}

Vol. XVII, 1948. Pp. 183, illustrated. Published î by the Research Department of the Hospital. Ios.

This book follows in the wake of its predecessors in producing, in less than 170 pages, a collection of $\frac{\circ}{3}$ very good articles dealing with various angles of chest disease. These articles show the various $c$ spheres of research and surveys carried out at the Brompton Hospital, are most interestingly written and it would be fair to say that nearly any medical reader apart possibly from the staff of the Brompto $\overrightarrow{0}$ Hospital would learn a considerable amount frot this volume. In addition to the clinical articles which vary from an interesting summary on the medical contraindications to flying by Kenneth Robson, to advances in thoracic surgery by N. R. Barrett, there is an interesting centenary review dealing with the history of the hospital.

In all, it may be said that this book is a most valuable asset to any physician's or chest surgeon's $\overrightarrow{\bar{O}}$ bookshelf, and serves a most useful purpose in $\exists$ keeping its readers up to date with modern trends in diseases of the chest.

\section{BLAKISTON'S NEW GOULD MEDICAL DICTIONARY}

Edited by Harold W. JoNes, M.D., Normand L. HoERR, M.D., and ARThur Osol, M.D. Pp. O xxviii + 1294, with 45 plates. London: H. K. ₹ Lewis and Co., Ltd. 1949. 45s.

This is a completely new work of reference and $D$ is the most ambitious so far attempted in the field. 을. In view of the enormous expansion of medicine and its allied sciences, the editors considered moderniza- $\sigma$ tion, however judicious, of Gould's Medical N Dictionary to be entirely inadequate. Starting, N therefore, from the basis of the fifth edition of this $\omega$ old and well-tried friend which since its first edition in 1890 has achieved a world reputation, the editors 0 have tackled their Herculean task courageously and $\mathbb{D}$ with discrimination. Having first jettisoned a $\stackrel{\mathcal{f}}{+}$ 'sizable number of worthless entries,' they pro- 0 ceeded to add an enormous amount of new material, keeping, as their first aim, exact definition in as $\mathbb{D}$ 